\title{
Status of the phasing out of the Chamber of Mines of South Africa Certificates of Competency
}

\author{
by H. Grobler* and J.A. Maritz ${ }^{\dagger}$
}

\section{Synopsis}

The Chamber of Mines of South Africa (CoMSA) Certificates of Competency (CoCs) were introduced to standardize stand-alone in-house qualifications for persons working in the South African Mining and Minerals Industries (SAM\&MS). When the Higher Education Qualification Framework (HEQF) Act was introduced in 2007, one of the unintended consequences was that it implied that CoMSA could no longer issue its OBET non-compliant CoCs. In response to these developments, the intention was to phase out CoMSA CoCs by establishing a deadline for the last entry for new candidates into the CoMSA CoC system at 31 August 2015, before it was finally recognized that these changes would have a wider impact in the SAM\&MS involving mine environmental control (MEC), rock engineering (RE), mine surveying, and other disciplines. Three institutes, namely the Institute of Mine Surveyors of South Africa (IMSSA), the South African National Institute for Rock Engineers (SANIRE), and the Mine Ventilation Society of South Africa (MVSSA) made a combined representation, and it was agreed that the said deadline could be extended to 31 August 2018. This means that the complete suite of 'new' (Outcomes Based Education and Training [OBET])-compliant qualifications must be registered on the appropriate level of the National Qualifications Framework and sub-frameworks by the South African Qualifications Authority (SAQA), and implemented by approved education and training providers and accredited by the respective Quality Councils (QCs). In the case of the South African Mining and Mineral Sector (SAM\&MS) the Mining Qualifications Authority (MQA), being the custodian of qualifications for the SAM\&MS in terms of Section 41,(3) of the Mine Health and Safety Act 1995 (MHSA), Act 27 of 1995 and Regulations as amended, supported by the relevant professional associations (PAs) will apply to the relevant $Q C$ to be appointed as Development Quality Partner (QDP) and/or Quality Assessment Partner $(\mathrm{AQP})$ to develop, implement and quality assure (QA) 'mining-technical related' qualifications. The application process to have an OBET-compliant qualification developed and registered on the NQF is tenuous at best, and it is anticipated that a minimum of two years will be required to achieve this for one level of Quality Council for Trades and Occupations (QCTO)compliant qualifications. The positive spin-off of this crisis is that 'learned societies' and PAs active in the SAM\&MS were drawn into the development and implementation of a range of recognized OBET-compliant occupational qualifications required to develop the knowledge and skills needed in the Industry. This paper outlines the requirements for such qualifications and outlines the progress made towards the development and implementation thereof.

Keywords

mining qualifications, curriculum development, accreditation, outcomesbased education and training.

\section{Introduction}

Chapter 4 of the Mine Health and Safety Act 1995 (MHSA), Act 27 of 1995 deals with tripartite institutions and in accordance of Section 41(3), a Mining Qualifications
Authority (MQA) is established to advise the Minister on qualifications, standards, assessments, examinations, quality assurance, and accreditation of mining qualifications. In this role the MQA is to advise the Minister on the registration of qualifications on the National Qualification Framework (Department of Mineral Resources, 2011). In Schedule 7 (g) (GNR 612 of 24 June 1998) it is determined that the Authority must 'assure the quality of education and training..., without itself being provider of education...'. The functions of the MQA is defined in Chapter $446(1)(\mathrm{a}-\mathrm{f})$ of the MHSA.

With the establishment of the NQF in 1995, three quality Quality Councils (QCS) were established for the setting of and quality assurance of competency standards. These Quality Councils are the Council for Higher Education (CHE), which deals with formal tertiary education on NQF levels 5 through 10; the Further Education and Training Quality Council (FETQC) (Umalusi), which deals with qualifications on NQF levels 1 through 4; and the Quality Council for Trades and Occupations (QCTO), which deals with qualifications on NQF Levels 1 through 8. The Occupational Qualifications Framework (OQF) was developed to address labour market needs in respect of occupations and was designed to provide occupational qualifications as well as the minimum access requirements for these qualifications. The OQF intends to provide clear articulation with qualifications in the general and further education framework and

\footnotetext{
* University of Johannesburg, South Africa.

₹ University of Pretoria, South Africa.

(c) The Southern African Institute of Mining and Metallurgy, 2017. ISSN 2225-6253. Paper received Apr. 2016; revised paper received Mar. 2017.
} 


\section{Status of the phasing out of the Chamber of Mines of South Africa Certficates of Competency}

seamless progression to the Higher Education and Training (HET) Framework. Occupational qualifications contain three distinctive components, namely; a knowledge component, a skills component, and a work experience component. (Mining Qualification Authority, 2016). The role of SAQA is to protect the integrity of the NQF and facilitate harmonization between the said sub-frameworks in order to promote 'seamless horizontal and vertical articulation and progression' through the different levels of the NQF. The QCTO system requires that a Community of Expert Practice (CEP), made up of practitioners active within a specific occupation, will be involved in standard setting (DQPS) and quality assurance (AQPs) of QCTO-compliant qualifications. This role was previously fulfilled by the Standard Generating Bodies (SGBs) under the original Skills Development Act. In the new context, the various PAs inclusive of the Institute of Mine Surveyors of South Africa (IMSSA, the Mine Ventilation Society of South Africa (MVSSA), and the South African National Institute for Rock Engineers (SANIRE) should be involved as the relevant CEPs for the qualification required for their respective occupations.

The ideal AQP should operate in close collaboration with the recognized industry-specific 'Learned Society' or PA in an attempt to complete the development, implementation and QA of occupational qualifications. The role of the appointed AQP is to:

> Set the national standard for the occupational competence described in the qualification

> Develop, maintain, and apply external assessment tools to ensure a standardized national process for achieving the qualification. This would include tools such as an item bank test. The positive legacy of the CoMSA CoC is that an excellent record of past assessment tools and question banks are available to develop into a new 'test bank' for external assessment. In this process, assessments for each qualification on the relevant level of the NQF, using Blooms taxonomy as the point of departure, must be developed. The AQP must determine policies and procedures for assessments. A schedule of assessment dates, criteria for assessment sites, and the accreditation of these sites must be compiled. The AQP can then register assessors and moderators (specified qualifications and experience and courses required)

> Evaluate results of the assessment and in collaboration with the QCTO, and deal with quality assurance issues for Providers.

> Research and evaluate the impact of the qualification and recommend actions to improve the impact in order to achieve the National Skills Strategy and contribute towards achieving the National Development Strategy.

The role of PAs is to ensure that their qualifications meets the competency and legislative requirements, ensure that the qualification will contribute to the maintenance of professionalism, and to advise on any changes that may be required to meet future occupational needs. The purpose of the National Skills Development Strategy (NSDS) is to create a national framework of learning that will facilitate access, mobility and progression in education and training. (Mining Qualifications Authority, 2016).

Using the abovementioned principle as the point of departure, the PAs stated, at a recent industry presentation, that 'Industry training was isolated and did not lead to nationally accredited qualifications.' CoMSA has been issuing CoCs since the 1970s. Although these CoCs have always had an excellent reputation and enjoyed recognition within the SAM\&MS, they do not comply with the requirements of the NQF system, i.e. they are not OBETcompliant qualifications registered on the appropriate level of the 10-level NQF.

As a result of the developments within the NQF and recent legislation, the CoMSA CoCs have to be phased out and replaced with OBET-compliant qualifications registered on the appropriate level of the NQF. The original intent of the phasing-out period was that the last enrolment of new candidates into the CoMSA system would take place on 31 August 2015. However, because the assessment system of the QCTO was not ready, this date was postponed until 31 March 2016 for the May 2016 examination, and then postponed again to August 2016 (Anderson, 2016).

Following a representation to the Executive of CoMSA, it was agreed to extend the deadline to the 31 December 2020. This agreement will see the last enrolment for new candidates into the system on 31 August 2018 (Mabena, 2016). At this point the QCTO-compliant qualifications must be in place for all the said mining-technical disciplines.

The mine surveying, mine environmental, and rock engineering disciplines are extremely reliant on the CoMSA certificates in order for persons in these fields to progress to the $\mathrm{CoC}$ as defined in the MHSA (Anderson, 2016). A significant percentage of persons working in these three fields are working full-time in industry and are by necessity forced to make use of 'distance learning' options in order to obtain a recognized industry qualification. A summary of the average number of persons sitting examinations for the various CoMSA certificates for the period 2009-2015 is given in Table I.

\section{Table I \\ Candidates per CoMSA Certificates of Competency (Source: CoMSA)}

\begin{tabular}{|l|c|}
\hline Certificate & Average 2009-2015 \\
\hline Elementary Mine Survey & 159 \\
Advanced Mine Survey & 119 \\
Advanced Mine Valuation & 97 \\
Mine Survey Draughting & 15 \\
Mine Environmental Control Intermediate & 112 \\
Mine Environmental Control & 71 \\
Strata Control Hard Rock & 149 \\
Strata Control Coal & 14 \\
Rock Engineering: Theory & 98 \\
Rock Engineering: Application & 86 \\
Rock Engineering: Hard Rock & 47 \\
Rock Engineering: Coal & 7 \\
Rock Engineering: Massive & 3 \\
Rock Engineering: Surface & 4 \\
\hline
\end{tabular}




\section{Status of the phasing out of the Chamber of Mines of South Africa Certficates of Competency}

A mine surveyor who has obtained the CoMSA Advanced CoC may, upon application, be accepted as a candidate for the Government Certificate of Competency (GCC) examinations. For mine environmental control (MEC)/mine ventilation and rock engineering practitioners, the advanced CoMSA CoCs are by regulation recognized as proof of competency required in accordance with the MHSA. The throughputs for these qualification have not been ideal.

\section{Unintended consequences - the HEQF and the COMSA CoC}

When the HEQF Act was introduced in 2007, it meant by implication that the CoMSA could no longer issue CoCs at Levels 5 through 8 as it would have to become recognized as an accredited HET provider. In response to these changes Grobler suggested that the COMSA CoC be modified in order to ensure articulation from the replacement OBET-compliant qualifications into the formal HE system. With the advent of the HEQF, the option of replacing the CoMSA CoCs with HEQF-compliant qualifications seemed plausible but would have to comply with the requirements of the new Skills Development Act 2008.

Using the mine surveying discipline as an example, the intention was to replace the CoMSA Elementary Certificate with a QCTO-compliant Higher Certificate (NQF Level 5) and the CoMSA Advanced Certificate with a QCTO-compliant Advanced Certificate (NQF Level 6). The provision of Level 2 through Level 4 qualifications would be addressed through the QCTO process. The said Levels 2 through 4 QCTOcompliant qualifications have been developed using the existing basic surveying and sampling curriculum and portions of the CoMSA Elementary $\mathrm{CoC}$. These two certificates were intended to replace the CoMSA CoC and offer an alternative to the current National Diploma which, in terms of the original HEQF Act, was considered to be a 240-credit, 2year full-time qualification, which did not seem feasible at the time. The University of South Africa (UNISA) planned to offer the said two qualifications. However, during the 2013 accreditation visit of the South African Council for Professional and Technical Surveyors (PLATO) to UNISA, the accreditation panel advised against these proposed certificates and proposed that the 2-year National Diploma be considered the preferred qualification. This suggestion had the unintended, serious repercussion in that no person would be able to complete a CoMSA CoC in less than two years through a distance learning mechanism. Although the intention of this recommendation seemed acceptable for the uninformed, it has left a large percentage of mining technical practitioners with low Grade 12 examination results without a route to obtain qualifications that could ultimately lead to acceptance for the GCC examinations. Although these changes were well publicized at the time, the original 2016 deadline set by CoMSA was not in any way adjusted to accommodate the said changes. This CoMSA decision affected not only the mine survey and sampling disciplines, but also the EMC and SC/RE disciplines. It should be noted that the survey draughting discipline was not considered at all in any of these arrangements.

\section{Deadlines}

The challenge remains to meet the required deadlines for the phasing out/replacing of the CoMSA CoC as a result of the requirements placed on the development of QCTO-compliant qualifications. These challenges include, inter alia: the registration of existing training providers; the development of an NQF Level 5 QCTO-compliant qualification for mine surveyors and mineral valuation practitioners; the development of an NQF Level 7 qualification to address the requirements for an appropriate Level 7 qualification and work experience required for acceptance as candidate for the GCC examinations for mine surveyors; and, most importantly, addressing the perceived gap in education, training, and development between the new suite of QCTO-compliant qualifications and the CoMSA CoC. It is argued that the deadline for the replacement of the CoMSA CoC should be extended to address this 12-18 month approval period for the registration of a QCTO-compliant qualification and to deal with learners who are still in the competency development process. The IMSSA is committed to supporting and/or facilitating this process as far as possible, but lacks the resources to effectively deal with the requirements since it relies on voluntary contributions from its members. As a result of the delays in the processes, the IMSSA approached CoMSA and requested that the deadline for the termination of the CoMSA CoC be extended in order to address any resultant time lag caused by the transition from the current CoMSA CoC to the 'new qualifications'.

\section{The recognition of the CoMSA CoC by tertiary Institutions}

The CoMSA CoC was introduced to standardize stand-alone in-house qualifications for persons working in the SAM\&MS. For this reason, most surveyors refer to this approach as the 'practical route' as studies are completed while employed in the SAM\&MS. Most mining houses in the 1970s and 1980s developed their own 'suites' of 'qualifications' in order to ensure quality in training and development for their employees. Unfortunately the CoMSA CoC was never evaluated for equivalency with OBET-compliant qualifications registered on the NQF and therefore does not enjoy recognition when a learner want to enter the mainstream academic route at a traditional university, university of technology, or combined university. With the introduction of the HEQF Act the Chamber could no longer offer these qualifications.

\section{Regulating the Mine Surveying occupation}

In order to ensure a commonality between the various minespecific competency requirements, CoMSA developed three CoCs that accommodated the three stages of competency required by a mine surveyor to progress to a point where he or she could be promoted to a senior position and become eligible to enrol as a candidate to the examinations for the GCC: Certificated Mine Surveyor. This 'suite' of CoMSA CoCs continues to enjoy strong support from the SAM\&MS. From figures obtained from CoMSA it appears that for the period 


\section{Status of the phasing out of the Chamber of Mines of South Africa Certficates of Competency}

2009-2015, an average 159 candidates attempted the Elementary Certificate: Mine Surveying and 119 candidates attempted the Advanced Certificate: Mine Surveying. Chapter $17(1)$ (b) of the MHSA defines a Competent Person:

> in the case of a surface mine where blasting does not take place, a person in possession of a mine surveyor's certificate of competency issued by the department;

or

- '... a person who has passed the examination for mining legislation as is required for the mine surveyor's certificate of competency issued by the Department and who is in possession of either:

(i) an Advanced Certificate in mine surveying issued by the Chamber of Mines of South Africa and who has at least three (3) years practical experience in mine surveying; or...

(ii) an Advanced Certificate in mine surveying issued by the Chamber of Mines of South Africa and who has at least three(3) years practical experience in mine surveying; or...

(iii) a person who has been assessed competent against a qualification recognized by the Mining Qualification Authority for this purpose. (DMR, 2011) are:

The CoMSA CoCs availale to mine surveyors and samplers

> Basic Certificate-Mine Survey and Sampling (NQF level 4)

> Elementary Certificate-Survey- and Sampling (NQF level 2)

> Advanced Certificate-Survey- and Mineral Valuation

- Certificate-Mine Survey Draughting, which has not been addressed at this point and is a matter that requires urgent remedial action to be taken to ensure that an equivalent OBET-compliant qualification will be provided for this occupation.

Statistics for five years of examinations, held twice a year, provided the throughput percentages shown in Table II.

A review of credits obtained by these four $\mathrm{CoC}$, when compared with the curriculum of the current National Diploma reveals the following:

> CoMSA CoC: Elementary Mine Survey provides 21.25 credits at level 5 on the NQF

> CoMSA CoC: Elementary Sampling provides 21.25 credits at level 5 on the $\mathrm{NQF}$
> CoMSA CoC: Advanced Mine Survey provides 21.625 credits at level 6 on the NQF (made up of 2.5 credits at level 5 and 19.125 credits at level 6 of the NQF respectively)

> CoMSA CoC: Advanced Mine Survey provides 24.5 credits at level 6 of the NQF (made up of 7.5 credits at level 5 and 17.0 credits at level 6 of the NQF respectively).

The total credit for the entire CoMSA CoC in mine surveying (including sampling/valuation) is therefore 93.625, which is short of the minimum of 120 credits for an NQF Level 5 'Higher Certificate'. It may be possible to reach the required 120 credits if notional hours of learning can be awarded to the trial survey component of the Advanced Certificate.

\section{What will replace the CoMSA CoC?}

It was originally intended that the $\mathrm{COC}$ in mine surveying be replaced by the HEQF-compliant Higher and Advanced Certificates. The Level 5 Higher Certificate (Mine Surveying) would replace the CoMSA Elementary Certificate and the Level 6 Advanced Certificate (Mine Surveying) was intended to replace the CoMSA Advanced Certificate. This process reached an advanced state of preparation before a seemingly unrelated decision relating to the reintroduction of the Blasting Certificate caused it to be abruptly terminated. Fortunately, while the HEQF-compliant qualifications were developed, two NQF Level 4 QCTO-compliant qualifications were developed in a parallel process. Since occupational qualifications are linked to occupations that are coded in accordance with the classification of the Organizing Framework Occupations (OFO) code for occupations, the qualification descriptors are mining technician with specialization (surveyor, mining). The QCTO-compliant qualifications consist of three distinct components, namely: theoretical, skills, and practical (portfolio). The two qualifications are:

1. NQF Level 4: SAQA 94870 Occupational Certificate: Mining Technician (Mining Sampler: Hardrock)

2. NQF Level 4: SAQA 94876 Occupational Certificate: Mining Technician (Mining Surveyor).

The foundational learning competency for these qualifications, articulation and Recognition of Prior Learning (RPL) based on an appropriate assessment either for entry or progression to other qualifications, must still be completed. The IMSSA intends partnering with the MQA in order to complete the required processes. This will require a team of

Table II

Throughput rate for Mine Surveying examinations (source: CoMSA)

\begin{tabular}{|l|c|c|c|c|c|c|}
\hline \multirow{2}{*}{} & \multicolumn{2}{|c|}{ Elementary } & \multirow{2}{*}{$\begin{array}{c}\text { Survey } \\
\text { Draughting }\end{array}$} & \multirow{2}{*}{$\begin{array}{c}\text { Advanced } \\
\text { Valuation }\end{array}$} & \multicolumn{2}{c|}{ Advanced Survey } \\
\cline { 2 - 3 } \cline { 5 - 7 } & Sampling & Surveying & Theory & Legislation \\
\hline $\begin{array}{l}\text { Average } \\
2009-2015\end{array}$ & $36 \%$ & $26 \%$ & $54 \%$ & $50 \%$ & $31 \%$ & $38 \%$ \\
\hline
\end{tabular}


Table III

Credit equivalence between a National Diploma and the CoMSA CoC (Grobler, 2016)

\begin{tabular}{|c|c|c|c|c|c|c|c|c|c|c|c|}
\hline \multicolumn{12}{|c|}{ Codes and Credits comparison for Chamber of Mines Elementary and Advanced } \\
\hline \multirow{2}{*}{$\begin{array}{l}\text { Course } \\
\text { N.Dip }\end{array}$} & \multirow{2}{*}{$\begin{array}{l}\text { Code } \\
440-1\end{array}$} & \multicolumn{2}{|c|}{ Semester Code } & \multirow{2}{*}{$\begin{array}{l}\text { Module Name } \\
\text { Quantitive Techniques } 1\end{array}$} & \multirow{2}{*}{$\begin{array}{r}\text { NQF Credits } \\
10\end{array}$} & \multirow{2}{*}{$\begin{array}{c}\text { NQF } \\
\text { Level } \\
5\end{array}$} & \multirow[t]{2}{*}{$\begin{array}{l}\text { Element } \\
\text { Survey }\end{array}$} & \multirow[t]{2}{*}{$\begin{array}{l}\text { Element } \\
\text { Valuation }\end{array}$} & $\begin{array}{l}\text { Advanced } \\
\text { Survey }\end{array}$ & $\begin{array}{l}\text { Advanced } \\
\text { Valuation }\end{array}$ & GCC \\
\hline & & s1 & BQT1112 & & & & & & & 5.0 & 5.0 \\
\hline N.Dip & $440-1$ & s1 & CSA121 & Communication Skills 1 & 10 & 5 & & & & & \\
\hline N.Dip & $440-1$ & S1 & EIR1111 & Computer Skills 1 & 5 & 5 & & & & & \\
\hline N.Dip & $440-1$ & S1 & MOT1111 & Mineral Exploitation & 17 & 5 & 4.25 & 4.25 & & & 17 \\
\hline N.Dip & $440-1$ & s1 & MTH121 & Mathematics 1 & 13 & 5 & & & & & 13.0 \\
\hline \multirow[t]{2}{*}{ N.Dip } & $440-1$ & s1 & MWT1111 & Science Mining 1 & 15 & 5 & & & & & \\
\hline & & & & TOTAL & 70 & & 4.25 & 4.25 & 0 & 5 & 35 \\
\hline N.Dip & $440-1$ & s2 & CAD1111 & Computer Aided Draughting 1 & 10 & 5 & & & & & \\
\hline N.Dip & $440-1$ & S2 & EDM1111 & Mechanical Engineering Drawing 1 & 10 & 5 & & & 2.5 & & 5.0 \\
\hline N.Dip & $440-1$ & s2 & ENM31-1 & Emironmental Management III & 10 & 5 & & & & & \\
\hline N.Dip & $440-1$ & s2 & MAS11-1 & Accounting Skills 1 & 10 & 5 & & & & 2.5 & 5.0 \\
\hline N.Dip & $440-1$ & s2 & MSY1111 & Minerals Survey 1 & 17 & 5 & 17.0 & & & & 17.0 \\
\hline \multirow[t]{2}{*}{ N.Dip } & $440-1$ & S2 & MTH231 & Mathematics 2 & 10 & 5 & & & & & \\
\hline & & & & TOTAL & 67 & & 17 & 0 & 2.5 & 2.5 & 27 \\
\hline$\overline{\text { N.Dip }}$ & $440-1$ & s3 & MGN21-1 & Engineering Management II & 13 & 6 & & & & & \\
\hline N.Dip & $440-1$ & s3 & MNM31-1 & Numerical Methods & 13 & 6 & & & & & \\
\hline N.Dip & $440-1$ & s3 & MSY2111 & Minerals Survey II & 17 & 6 & & & 17.0 & & 17.0 \\
\hline N.Dip & $440-1$ & S3 & MVN1111 & Mineral Valuation 1 & 17 & 5 & & 17.0 & & & 17.0 \\
\hline \multirow[t]{2}{*}{ N.Dip } & $440-1$ & s3 & MWG2111 & 1 Mining Geology II & 10 & 5 & & & & & 10.0 \\
\hline & & & & TOTAL & 70 & & 0 & 17 & 17 & 0 & 44 \\
\hline$\overline{\text { N.Dip }}$ & $440-1$ & S4 & MSG3121 & Structural Geology III & 10 & 6 & & & & & 10.0 \\
\hline N.Dip & $440-1$ & $\$ 4$ & MSS21-1 & Statistics - Mining II & 13 & 6 & & & & & 13.0 \\
\hline N.Dip & $440-1$ & S4 & MSY3111 & Minerals Survey III & 17 & 6 & & & 2.125 & & 4.25 \\
\hline N.Dip & $440-1$ & S4 & MVN2111 & Mineral Valuation II & 13 & 6 & & & & 17.0 & 17.0 \\
\hline \multirow[t]{2}{*}{ N.Dip } & $440-1$ & \$4 & MGN32-1 & Engineering Management III & 15 & 6 & & & & & \\
\hline & & & & TOTAL & 68 & & 0 & 0 & 2.125 & 17 & 44.25 \\
\hline B.Tech & $728-1$ & S5 & ACS41-1 & Applied Computer Skills IV & 10 & 7 & & & & & \\
\hline B. Tech & $728-1$ & s5 & GEO411 & Geostatistics N & 10 & 7 & & & & & 2.5 \\
\hline B. Tech & $728-1$ & S5 & MIN21-1 & Mining II & 15 & 7 & & & & & \\
\hline \multirow[t]{2}{*}{ B. Tech } & $728-1$ & S5 & MSL41-1 & Mineral Survey Legislation IV & 10 & 7 & & & 5 & & 10.0 \\
\hline & & & & TOTAL & 45 & & 0 & 0 & 5 & 0 & 12.5 \\
\hline B.Tech & $728-1$ & S6 & GEOP411 & Geostatistics Project N & 13 & 7 & & & & & 13.0 \\
\hline B. Tech & $728-1$ & S6 & MES41-1 & Mining Economics $\mathrm{N}$ & 10 & 7 & & & & & 10.0 \\
\hline B. Tech & $728-1$ & S6 & MTL3211 & Mining Technical Services III & 13 & 7 & & & & & \\
\hline \multirow[t]{3}{*}{ B. Tech } & $728-1$ & S6 & PDS41-1 & Precise Deformation Surveys N & 13 & 7 & & & & & \\
\hline & & & & TOTAL & 49 & 28 & 0 & 0 & 0 & 0 & 23 \\
\hline & & & & & & & 21.25 & 21.25 & 26.625 & 24.5 & 185.75 \\
\hline
\end{tabular}

Table IV

Survey qualification models (source: Grobler )

\begin{tabular}{|c|c|c|c|c|c|}
\hline Level & $\begin{array}{c}\text { Chamber of Mines } \\
\text { approximate }\end{array}$ & Old Qualifications & \multicolumn{3}{|c|}{ New Qualifications } \\
\hline NQF Level 10 & & & & & $\begin{array}{l}\text { Philosophiae } \\
\text { Doctor }\end{array}$ \\
\hline NQF Level 9 & & & & & Masters Degret \\
\hline NQF Level 8 & & $\begin{array}{l}\text { Bachelor of } \\
\text { Technology }\end{array}$ & & & Honours Degre \\
\hline NQF Level 7 & $\begin{array}{l}\text { Govt. Cert. of } \\
\text { Competency }\end{array}$ & \multirow{3}{*}{ National Diplom } & & & \multirow{3}{*}{$\begin{array}{c}\text { Bachelor of } \\
\text { Mine Surveying } \\
\text { or } \\
\text { Bachelor of } \\
\text { Engineering } \\
\text { Technology }\end{array}$} \\
\hline NQF Level 6 & COM Advanced & & $\begin{array}{c}\text { SAQA } \\
\text { Mine Survey } 6\end{array}$ & & \\
\hline NQF Level 5 & COM Elementary & & $\begin{array}{c}\text { SAQA } \\
\text { Mine Survey } 5\end{array}$ & 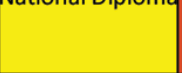 & \\
\hline NQF Level 4 & COM Basic & Grade 12 & $\begin{array}{c}\text { SAQA } \\
\text { Mine Survey } 4\end{array}$ & Grade 12 & Grade 12 \\
\hline
\end{tabular}




\section{Status of the phasing out of the Chamber of Mines of South Africa Certficates of Competency}

subject and technical experts or CEPs to develop the necessary learning materials and assessment guides. These two registered Level 4 qualifications will still require:

1. Training providers that have been accredited by the approved AQP

2. An item-bank test and external assessments must be developed

3. The split between the content in the learnership (per cent theory and per cent practical) must be registered with the Department of Labour (DOL)

4. The AQPs must prepare examination papers, model answers, and assessment tools.

The need to develop a Level 7, second-stage qualification for graduates prior to their acceptance as candidates to the GCC examination has been identified in this process. This crucial issue still needs to be finalized.

\section{CoC in Mine Environmental Control (MEC)}

The MEC occupation/practice has been regulated by legislation since 1917, when the first regulations under the Mines and Works Act that required the appointment of dust inspectors were promulgated. Soon, other occupational environmental issues such as noise, illumination, thermal environment, airborne pollutants, radiation, and flammable gases were added to the responsibilities of the MEC practitioner. The MEC practitioner is also tasked with the design and management of fire prevention, detection, and firefighting strategies. Currently these responsibilities are set out in Section 12 of the MHSA and regulations (Beukes, 2016). The CoMSA CoCs in MEC are referred to in the regulations of the MHSA, thereby defining the CoMSA CoC as proof of competency. For this discipline there are two such CoCs, namely;

> Intermediate Certificate in MEC (considered equivalent to Level 4 on the NQF), which consists of a practical and two written examinations (paper 1 and paper 2)

- Certificate in MEC (considered equivalent to Level 6 or 7 on the NQF), which consists of six papers.

The $\mathrm{COC}$ in MEC is required by the MHSA for persons who are responsible for environmental control at a mine. Regulation 22.15(5) (a) that the Competent Person referred to in regulations 5.1(1), 9.2(3), and 16.1(1), depending on the nature of the mine, should be in possession one of the following:

i) A valid CoMSA COC in MEC

ii) A valid CoMSA Intermediate CoC in MEC.

The examination for the Intermediate $\mathrm{CoC}$ is a prerequisite for entry into the examinations for the CoMSA Certificate in MEC. Statistics for five years of these examinations, held twice a year, are shown in Table V.

These figures indicate an average pass rate of $36 \%$ for the Intermediate Certificate and $28 \%$ for the Certificate in MEC.

\section{What will replace these CoMSA CoCs?}

The CoCs in MEC are unique to the SAM\&MS and the number of candidates is consequently limited. As a result, there is not enough critical mass for universities to register a standalone qualification in this discipline and therefore most of the feed into the profession is sourced from on-the-job distance learning candidates. Work is currently in progress to expedite the completion and implementation of the NQF Levels 3 and 4 QCTO-compliant qualifications. An NQF Level 6 qualification has been developed in collaboration with the University of the Witwatersrand (Wits), which will consist of seven oneweek modules offered at the University. The curriculum of the qualification will consist of a written examination two weeks after the conclusion of lectures and the submission of an assignment report two weeks after examination. The curriculum will consist of seven modules:

> Module 1-Fluid flow dynamics

> Module 2-Thermal engineering

> Module 3-Planning, applied economics, technical literature, and information management

> Module 4-Risk management, fire and explosions, gases, statistics

> Module 5-Occupational hygiene - (Wits to help enhance the level of this module)

> Module 6-Legislation

> Module 7-Mathematics.

The final step will be the development and registration of an QCTO-compliant NQF Level 7 qualification and an appropriate plan and schedule for the development thereof (Beukes, 2016)

\section{CoC in Rock Mechanics/Engineering}

The CoMSA CoC in Rock Mechanics (RMC) was introduced in the 1970s to standardize and regulate the various competency models used by South African mining houses. The weakness of the independent 'mining house systems' was that it limited the movement and reciprocal recognition of rock engineering practitioners within the SAM\&MS. Based on this shortcoming, the Group Rock Engineering Committee (one of CoMSA's sub-committees) decided to initiate a CoC in Rock Mechanics for tabular mining in 1977. By 2002 the

Table $\mathrm{V}$

Throughput rate for Mine Environment Control examinations

\begin{tabular}{|l|c|c|c|c|c|c|c|c|}
\hline & $\begin{array}{c}\text { Interm. } \\
\text { P1 }\end{array}$ & $\begin{array}{c}\text { Interm. } \\
\text { P2 }\end{array}$ & $\begin{array}{c}\text { Paper } \\
\mathbf{1}\end{array}$ & $\begin{array}{c}\text { Paper } \\
\mathbf{2}\end{array}$ & $\begin{array}{c}\text { Paper } \\
\mathbf{3}\end{array}$ & $\begin{array}{c}\text { Paper } \\
\mathbf{4}\end{array}$ & $\begin{array}{c}\text { Paper } \\
\mathbf{5}\end{array}$ & $\begin{array}{c}\text { Paper } \\
\mathbf{6}\end{array}$ \\
\hline $\begin{array}{l}\text { Average } \\
2009-2015\end{array}$ & $47 \%$ & $26 \%$ & $16 \%$ & $23 \%$ & $20 \%$ & $35 \%$ & $35 \%$ & $37 \%$ \\
\hline
\end{tabular}




\section{Status of the phasing out of the Chamber of Mines of South Africa Certficates of Competency}

CoMSA RMC was incorporated into the regulations of the MHSA. Post-2002, the original RMC made provision limited to the practice areas of underground tabular and coal mines. The provisions of the RMC were subsequently expanded in October 2007 to include CoCs for massive underground and surface mining (Lucas, 2016). The inclusion of the CoC in the definition of a Competent Person in Section 22.14.1(8) of the MHSA implies that the RMC is the prescribed competency requirement for a RM/RE practitioner in the SAM\&MS. The following CoMSA CoCs, subdivided into appropriate specialization areas, are provided for the RM/RE discipline:

$>\mathrm{CoC}$ in Strata Control:

i. Hard rock

ii. Coal

$>$ CoC in Rock Mechanics:

i. Metalliferous mines

ii. Coal mines

iii. Massive underground mines

iv. Surface mines.

Section 22.14.1(8) of the MHSA requires competent $\mathrm{RM} / \mathrm{RE}$ practitioners to be in possession of a valid, appropriate RMC to be eligible to perform the following work:

'At every underground mine where a risk of rock bursts, rock falls or roof falls exists, and at every other mine where a significant risk of rock bursts, rock falls or rooffalls exists, the employer must ensure that the input of a competent person is properly and timeously considered and integrated into mine design, planning and operations.'

The said Competent Person is defined as follows in Section 22.14.1(8) of the regulations:

'a person who is at least in possession of either the Chamber of Mines Certificate in Rock Mechanics [Metalliferous Mines], or the Chamber of Mines Certificate in Rock Mechanics [Coal Mines], whichever is appropriate for the type of mine concerned.
The relevant Strata Control Certificate for hard rock or coal mining is a prerequisite for obtaining the RMC.

Following on the RMC written exams (papers 1 and 2), a candidate can complete the $\mathrm{CoC}$ examinations in either hard rock, coal, massive, or surface mining by submitting a portfolio of evidence proving competence and completing a practical examination. Statistics for five years of these examinations, held twice a year, indicate the pass rates in Table VI.

The implicit reference in the regulations of the MHSA to the CoMSA CoC underlines the crucial importance of these qualifications within the SAM\&MS and the implication that this needs to remain so for the foreseeable future. It should, however, be noted that a process is currently underway to update and revise the legislation to cater for a 'new' (OBETcompliant) qualification registered on the $\mathrm{NQF}$ when the current CoMSA CoC is discontinued. The proposed 'new competency model' also needs to make provision that a $\mathrm{RE} / \mathrm{RM}$ practitioner registered in the appropriate category with a statutory body such as the Engineering Council of South Africa (ECSA) or the South African Council for Natural Scientists SACNASP) be eligible to practice as a Rock Mechanic/Engineer on an operation in the SAM\&MS.

\section{Replacement of the CoMSA RMC}

Indications are that the current CoMSA RMC will in time be replaced by appropriate QCTO-compliant NQF Level 3, 4, and 6 qualifications. At the entry level for the hard rock sector, a Level 3 occupational qualification will be required for an Observer (SAQA ID: 96464). This qualification carries a credit loading of 108 (i.e. equivalent to 1080 notional hours of learning). The RMC will be replaced with an appropriate Level 4 occupational qualification, similar to the Level 3 occupational qualification, which has also already been registered by the QCTO. The said Level 4 occupational qualification will provide for the Hardrock (SAQA ID: 94038)

Table VI

Throughput rate for Rock Engineering examinations (source: CoMSA)

\begin{tabular}{|l|c|c|c|c|c|c|c|c|}
\hline & $\begin{array}{c}\text { S/C } \\
\text { Met. }\end{array}$ & $\begin{array}{c}\text { S/C } \\
\text { Coal }\end{array}$ & $\begin{array}{c}\text { Paper 1 } \\
\text { Theory }\end{array}$ & $\begin{array}{c}\text { Paper 2 } \\
\text { Application }\end{array}$ & $\begin{array}{c}\text { Paper 3.1 } \\
\text { Hard Rock }\end{array}$ & $\begin{array}{c}\text { Paper 3.2 } \\
\text { Coal }\end{array}$ & $\begin{array}{c}\text { Paper 3.3 } \\
\text { Massive mining }\end{array}$ & $\begin{array}{c}\text { Paper 3.4 } \\
\text { Surface }\end{array}$ \\
\hline $\begin{array}{l}\text { Average } \\
2009-2015\end{array}$ & $30 \%$ & $12 \%$ & $12 \%$ & $25 \%$ & $25 \%$ & $33 \%$ & $28 \%$ & $32 \%$ \\
\hline
\end{tabular}

Table VII

Occupational qualifications in Strata Control registered on the NQF (source: Maritz, 2016)

\begin{tabular}{|c|c|c|c|}
\hline $\begin{array}{l}\text { SAQA } \\
\text { ID }\end{array}$ & Qualification & $\begin{array}{l}\text { NQF } \\
\text { Level }\end{array}$ & Credits \\
\hline 96464 & Occupational Certificate: Mining Technician (Strata Control Observer: Underground Hardrock) & 3 & 108 \\
\hline 94038 & Occupational Certificate: Mining Technician: (Strata Control Practitioner: Underground Hardrock) & 4 & 198 \\
\hline 94878 & Occupational Certificate: Mining Technician: Strata Control Practitioner (Coal) & 4 & 264 \\
\hline
\end{tabular}




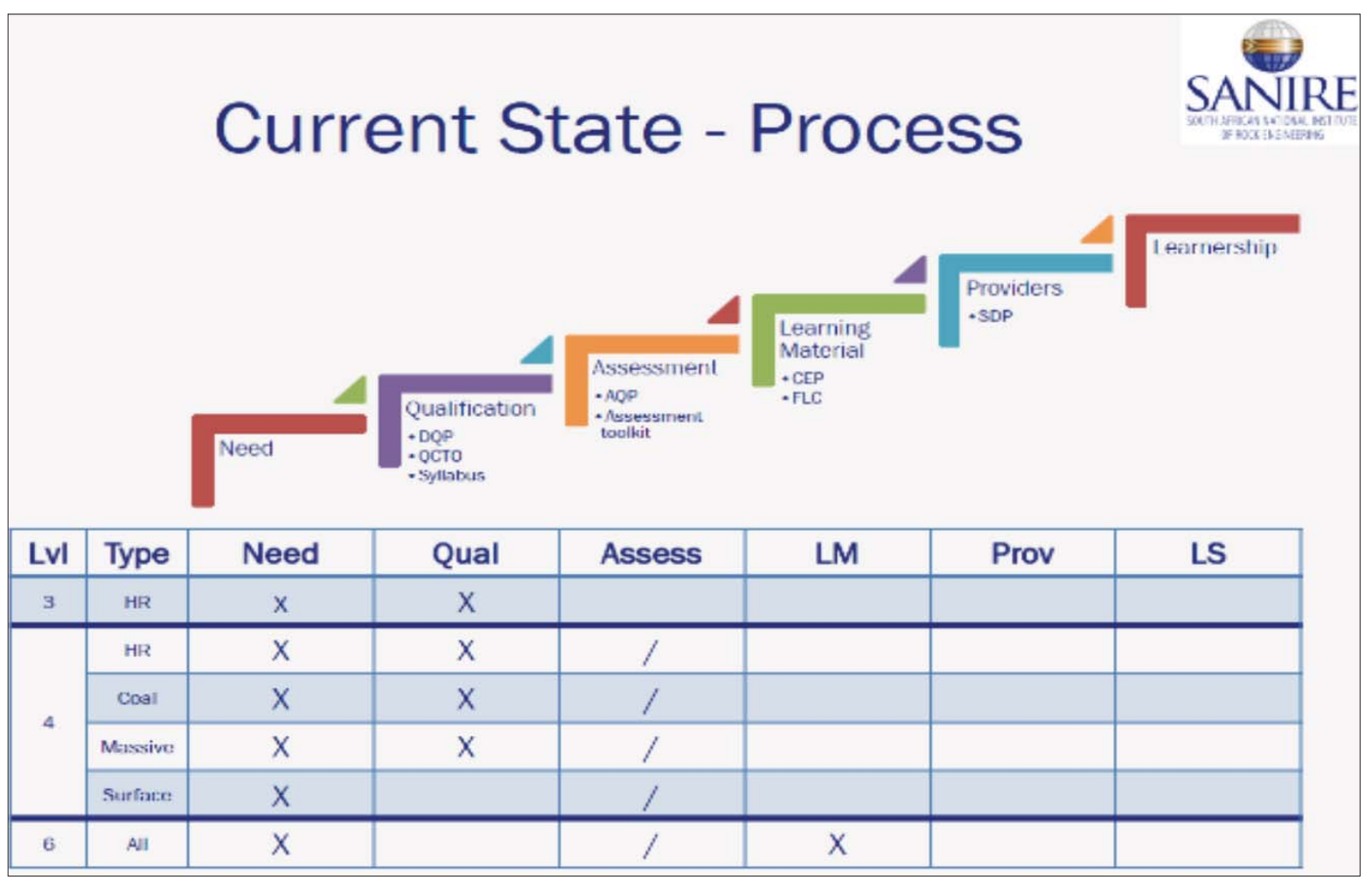

Figure 1-SANIRE current state and progress (source: Maritz, 2016)

or Coal (SAQA ID: 94878) practice areas, as is the case with the current RMC. The credits for the said two Level 4 occupational qualifications are 198 for hard rock and 264 for coal. The reason for more credits being associated with the coal qualification is that some of the Hardrock observer material, which may already have been acquired by hard rock practitioners during their Level 3 learning, provides them with Recognition of Prior Learning (RPL) in relation to the requirements of the Level 4 occupational qualification. The registered occupational qualifications are summarized in Table VII.

The RMC will be replaced by a Level 6 qualification, the application for development of which has been submitted to the QCTO jointly by the MQA and SANIRE. The development of the said occupational qualification has been approved by QCTO as a prioritized occupation and development is currently in progress (Figure 1). The said qualification will be registered under the OFO code 311701 as a specialization (i.e. Rock Engineering Officer) under the Mining Technician occupation.

The abovementioned qualifications need to be in place by 2020 when the current CoMSA CoC will be discontinued.

\section{Four essential processes to be completed}

In order for RE/RM practitioners in the three practice areas to complete the transition to the 'new qualifications' and be registered on the appropriate level of the 10-level NQF, the QCTO, in collaboration with the MQA as DQP and AQP, CoMSA, and the relevant PAs, needs to complete the following four essential processes.

\section{Approved DQP develops qualification}

a) An occupational profile describing the occupation (occupational descriptor) and the tasks, practical skills, and work experience must be developed. Qualifications must be 'fit for purpose' and reflect the requirements of the SAM\&MS. Occupational qualifications must reflect three forms of learning, including a minimum of $20 \%$ of the credits for knowledge and theory, a minimum of $20 \%$ for practical skills, and the balance allocated to the 'appropriate needs of the particular occupation' (Mining Qualification Authority, 2016)

b) A planned curriculum that includes the specifications for the knowledge, practical skills, and work experience modules, and the work experience record must be developed. An external assessment specification must be developed for the respective curriculum

c) The learning curriculum, which includes the sequence of learning, the learning processes and methods, and the formative assessment criteria must be developed

d) The development of learning material comprising facilitator guides, learning resources, learning tools, presentation material, lesson plans, and assessment tools must be completed.

\section{Establish Assessment Quality Partner (AQP)}

Coupled with the relevant MHSA regulations and the specific reference in Chapter 17 to the provisions in respect of the role, functions, and responsibilities. the MQA is ideally positioned to be appointed as the AQP for the proposed new 


\section{Status of the phasing out of the Chamber of Mines of South Africa Certficates of Competency}

occupational qualifications. Training providers are required to be accredited through an AQP and registered with the QCTO. The QCTO is to perform a 'light touch' accreditation of training providers, assessing on key points in the learning process but not the entire process (Mining Qualification Authority, 2016). The assessment process will address four areas: namely the written assessment, evaluation of practical skills, evaluation of projects or assignments, and evaluation of job performance. Such assessments will address the knowledge, skills, and work experience components of a qualification.

\section{Enabling delivery}

a) It is intended that the delivery strategy for the new occupational qualifications be discussed in a workshop with the providers in order to map the proposed curriculum to the content of the current CoMSA CoCs to ensure that the curriculum is relevant and updated

b) Guidelines for the development of the new learning material must be developed in this forum

c) The accreditation of registered providers will require cooperation between the MQA and the relevant PAs, subject to the guidance of the QCTO, to ensure that this process does not delay the phasing in of the new occupational qualifications. Progress with the registration of providers is currently unsatisfactory.

\section{Registration of learnerships}

Learners will be able to register for the new occupational qualifated that this process may take in excess of two years to complete successfully, based on the experience of one of the PAs.

\section{The action plan for the short to mid-term}

A meeting was scheduled with the Executive of CoMSA to request the extension of the phasing out date by one year in order to facilitate the introduction of the new occupational qualifications. Concerns were raised in respect of the expeditious conclusion of the process to register qualifications and achieve all the goals set by the QCTO. Since CoMSA was sympathetic to the request, a one-year extension was granted (Mabena, 2016). This extension will provide sufficient time to develop the qualifications in a systematic, effective, and efficient manner that will meet the requirements of the SAM\&MS, the MQA, the QCTO, and the relevant PAs.

The deliverables that must be met for the new suite of qualifications include the following:

1. Finalize the blueprints for the qualifications for each Exit Level Outcome (ELO):

a. The blueprints for the MEC, Sampling, and Mine Surveying qualifications have been completed. The blueprint for the RE/RM practice area was expected to be completed by 25 May 2016 , following which it would be ready for approval and implementation (Anderson, 2016)

b. The NQF Levels 4, 5, and 6 occupational qualifications for the Mine Survey, Mine MEC, and RE/RM qualifications must be completed and replace the current CoMSA CoCs before the 2020 deadline

c. The envisaged NQF Level 7 occupational qualifications for the Mine Surveying practice area, leading towards eligibility to enrol for the GCC examinations must be developed and put in place with the support of the stakeholders in the SAM\&MS and the DMR Commission of Examiners (Grobler, 2016)

2. Discuss these blueprints with the QCTO and obtain approval

3. Develop five sets of assessment tools, including questions and memoranda for these questions.

a. The assessment tools, including the question papers, for the occupational qualifications in MEC, Sampling, and Mine Surveying have been completed. The assessment tools for the RE/RM qualifications were completed on 23-25 May 2016 (Anderson, 2016). This is now ready for approval and implementation

b. A study of six models of competency evaluation identified a number of common aspects that can be developed into a comprehensive model that should be more effective than the written examination process currently favoured by some countries (Grobler, 2016). The portfolio of evidence and examination procedures for this proposed NQF Level 7 'second-stage' occupational qualification for mine surveyors must be agreed upon by the relevant stakeholders and completed

4. Moderate the assessment tools through a work session

5. Finally, agree on the assessment tools and publish an exemplar of these assessments.

\section{Conclusions}

The implication of not addressing the transformation of the current qualifications framework for mining-technical occupations in the SAM\&MS would be a shortage of competent practitioners in the Mine Environmental Control (MEC), Rock Engineering (RE), and Mine Surveying disciplines (occupations) as well as other related occupations. A delay in the development of the new OBET-compliant qualifications could result in an inappropriate and unacceptable lag period between the phasing out of the CoMSA CoCs and the introduction of the new suite of OBETcompliant occupational qualifications. Such a situation may impact on individuals starting their careers now, since there would be no process available for them to obtain suitable and recognized qualifications that will underpin progression to the different occupations. This would introduce a risk at a time where vocational skills and qualifications may not be seen as a priority in the current economic downturn, but will certainly have a significant impact on the availability of competent persons who can fill the different mining-related occupations in the SAM\&MS in the future. 


\section{Status of the phasing out of the Chamber of Mines of South Africa Certficates of Competency}

Competency is considered to be the culmination of education, skills, knowledge, and experience that enables practitioners in the SAM\&MS to interpret situations in a manner that would reduce occupational health and safetyrelated risks and to avoid any significant $\mathrm{OH} \& \mathrm{~S}$ risks in the execution of their duties. The process of replacing recognized CoMSA CoCs has provided the affected occupations/ practitioners with an ideal opportunity to reflect upon and rectify any issues with the current CoCs through the development of new OBET-compliant occupational qualifications. Persons entering their respective occupations/professions should henceforth be enabled through the best methods of competency development that will be recognized not only in the SAM\&MS, but also by tertiary education institutions in South Africa. The concern that a gap will be created during period between the introduction of the new suite of OBET-compliant qualifications and the phasing out/replacement of the CoMSA CoCs is, fortunately, being addressed. The positive spin-off of this crisis is that the relevant 'Learned Societies' and PAs involved in the SAM\&MS were forced to get involved with the development and implementation of the necessary portfolio of recognized vocational qualifications to enable, educate, and train practitioners within the SAM\&MS. Despite the current economic downturn, the new envisaged range of occupational qualifications will have a positive impact on the sustainability of the various occupations and professions and ensure the continued availability of competent practitioners in these scarce skills to sustain the future of the Industry.

The extension of the deadline for the phasing out of the CoMSA CoCs has provided an essential respite for all those that make use of Competent Persons who are in possession of these well-respected and recognized industry CoCs. It is essential that the momentum gained over the past 18 months be maintained and exploited in order to establish new OBETcompliant qualifications and education providers well in advance of the new deadline. The further advantage of replacing the CoMSA CoCs with OBET-compliant qualifications registered with SAQA at the appropriate level on the NQF, in that persons may eventually be absorbed into 'mainstream' tertiary education, must not be underestimated. The new occupational qualifications will enable a system that will enhance mobility and recognition not only nationally, but also internationally. The study completed on behalf of the MQA by the University of Johannesburg on the throughput rates of the CoCs and the report by Cheadle, Thompson, and Haysom should be considered and implemented.

\section{The new competency and regulatory model for the SAM\&MS}

The implementation of a New/Futures, Competency, and Regulatory Model for the SAM\&MS is paramount for the sustained provision of competent practitioners for the relevant occupations and professions as proposed by the 2004 international benchmarking in respect of Regulatory Practice in other relevant countries, emulated by the Cheadle, Thompson, and Haysom report and the University of Johannesburg report on the throughput rates of certain CoCs.
The 'New Model' proposes the following transformatory interventions:

> Replacement of the relevant CoMSA CoCs as well as the relevant CoCs currently issued by the DMR with appropriate OBET-compliant qualifications registered by the relevant $\mathrm{QC}$ at the appropriate level of the 10level NQF

Supported, where necessary, by an appropriate DMRdriven regulatory (Licence-to-Practice (LtP)) system

\section{or}

> Replacement of selected CoMSA CoCs as well as relevant CoCs ('the big five') issued by the DMR with registration in the appropriate category with a Statutorily Established Body inclusive of the ECSA, SACNASP, and the SAGC as the preferred competency determination mechanism ( the 'New Competency and Regulatory Model for the SAM\&MS'),

Supported, where necessary, by an appropriate DMRdriven regulatory (Licence-to-Practice (LtP)) System.

\section{References}

Anderson, C. 2016a. Chamber of Mines Certificates Notification No. 1, January 2016. Johannesburg.

Anderson, C. 2016b Paper for comment. (H. Grobler, interviewer). 29 April.

BeuKes, M. 2016. Qualifications in relation to the Mine Environmental Control certificate and the development there of aligned to the NQF. Mine Ventilation Society of South Africa, Johannesburg.

ChEAdLe, Thompson, And Haysom

DepartMent of Mineral Resources (DMR). 2011. Mine Health and Safety Act No 29 of 1996. i ,27 May 2011. Pretoria.

GrobleR, H. 2013. 117 years of education for mine surveyors. Institute of Mine Surveyors of South Africa.

GRoBleR, H. 2016. Can an examination guarantee competency? A critical review of international second stage qualification models leading to a sum-mative competency assessment. Proceedings of the International Society of Mine Surveyors Conference 2016, Brisbane. International Society of Mine Surveyors.

LUCAS, J. 2016. Concerns regarding the definition of a competent person in terms of Regulation 22.14.1(8) of the Mine Health and Safety Act, Act 29 of 1996. South African National Institute of Rock Engineering https://www.sanire.co.za/component/docman/cat_view/106-keydocuments? Itemid $=230$

Mabena, V. 2016. Phasing out period of the Chamber of Mines certificates. Chamber of Mines of South Africa, Johannesburg.

Mining Qualifications Authority. 2016. The Occupational Qualification Framework. From curriculum to implementation. Presentation at a work session with the Department of Mineral Resources. 